\title{
Fostering house mice onto rats and deer mice: Effects on response to species odors
}

\author{
KARL L. WUENSCH \\ Miami University, Oxford, Ohio
}

\begin{abstract}
Newborn wild house mice (Mus musculus) were fostered upon maternal conspecifics, prairie deer mice (Peromyscus maniculatus bairdi) or laboratory rats (Rattus norvegicus). Male subjects were weaned into individual cages, in which they remained until testing commenced. At 35 days of age, subjects were given a four-choice test in which they had the opportunity to investigate tunnels scented with clean wood chips or with chips soiled by an adult male conspecific, deer mouse or rat. Compared to the Mus-nursed and Peromyscus-nursed mice, Rattus-nursed mice were more active during the test and less reluctant to investigate the Rattus-scented tunnel. These results were replicated in a two-choice test (Mus- vs. Rattus-scented tunnels) that included a group of mice fostered onto conspecifics, but with Rattus scents present in the maternity cage through out the nursing period. Early exposure to the scent of Rattus had no significant effects on the responses of Mus-nursed mice to the scent of Rattus.
\end{abstract}

Many studies have demonstrated that cross-species fostering can affect both olfactory preferences and social behaviors in rodents (see the review by D'Udine \& Alleva, 1983, and more recent studies by Carter \& Brand, 1986; McGuire, 1988; McGuire \& Novak, 1987; and Wuensch, 1986). It seems likely that altered experience with conspecific and foster-specific scents is the critical determinant of the effect of cross-species fostering on later response to such scents. Altering a rodent's early experience with scents has often been shown to affect its later response to such scents (Fillion \& Blass, 1986; Mainardi, Marsan, \& Pasquali, 1965; Marr \& Lilliston, 1969), especially when the scents were paired with maternally provided primary reinforcers (Galef, 1982). Since scents are greatly involved in rodents' social behaviors (Brown, 1985), some of the effects of cross-species fostering on social behaviors may be mediated by altered response to scents. Exposing infant house mice or deer mice to the other species' odors has been demonstrated to affect later interspecific fighting (Stark \& Hazlett, 1972).

While experience with specific scents may be an important factor in the effect of cross-species fostering, it is not likely the only important factor. One species' parental behavior may differ greatly from another's. For example, McGuire (1988) found that prairie voles differed significantly from meadow voles on six of the seven parental behaviors she studied. Such specific differences in parental care are expected to cause differences in the de-

This report is based on a dissertation submitted in partial fulfillment of the requirements for the PhD degree in experimental psychology at Miami University. I wish to acknowledge the assistance and support provided by the director of the dissertation, the late Patrick J. Capretta. Requests for reprints should be mailed to K. L. Wuensch, Department of Psychology, East Carolina University, Greenville, NC 27858-4353 (e-mail: pswuensc@ecuvm1.bitnet). velopment of the young, including cross-species-fostered young. One example of an effect of cross-species fostering that seems much more likely to be due to specific differences in parental care than to specific differences in scent is the effect on aggressiveness reported by Huck and Banks (1980). They found that brown lemmings were made more aggressive by being fostered onto a more aggressive species, collared lemmings, with the increased aggressiveness being displayed toward both brown and collared lemmings.

The present experiments investigated how fostering wild-strain male house mice onto two different species of rodents affected their responses to species scents. The experiments were designed to separate the effects of altered exposure to specific olfactory stimuli from the effects of specific differences in parental care. If early isolation from adult conspecific scents is most important, then one would expect that the effects of cross-species fostering would not vary across different foster species (unless one foster species smells more like house mice than does the other foster species). If specific differences in parental care or experience with foster-specific stimuli are most important, then the effects of fostering should vary across foster species.

\section{EXPERIMENT 1}

Male house mice may be either attracted to or repelled by the scent of other male house mice, depending on which part of the body produced the scent, the dominance status of the scent donor and subject, whether the donor has recently been stressed, the history of the subject, and other factors (Brown, 1985). Field research has indicated that wild house mice are attracted to traps that are scented with soiled bedding collected from dominant (not stressed) male house mice (Wuensch, 1982). Experiment 1 was de- 
signed to test the choice behavior of cross-species-fostered house mice when presented with areas scented with house mouse, deer mouse, and rat scents.

\section{Method}

Subjects. Wild house mice (Mus musculus) and prairie deer mice (Peromyscus maniculatus bairdi) that had been trapped in barns and in and around grain storage depots near Oxford, Ohio, were used to establish a colony at Miami University. In addition, laboratory rats (Sprague-Dawley albino Rattus norvegicus) were obtained from the Psychology Department's colony. The three species were maintained in separate rooms. Food (Charles River RMH 2000) and water were continuously available.

Breeding and fostering. Experienced breeders were paired for a 2-week cohabitation period, after which the females were removed and individually housed. The bedding (Ab-sorb-dri wood chips) was changed at this time.

The pups were fostered on days during which at least 1 rat, 1 deer mouse, and 2 house mice had given birth to the required number of pups. The pups were removed from their mothers within $24 \mathrm{~h}$ of birth. All house mouse pups born on a given day were pooled, sexed, and then randomly assigned to conditions. Each Mus mother and each Rattus mother received 4 male and 2 female Mus pups. Each Peromyscus mother received 2 male and 1 female Mus pup. Rattus and Peromyscus mothers also each kept 1 male and 1 female conspecific pup.

Pilot work had indicated that the inclusion of conspecific pups in the Rattus and Peromyscus mothers' foster litters is necessary to assure a high survival rate. The somewhat unequal litter sizes also contribute to pup survival. Peromyscus do not do well with more than five pups, and Rattus do not accept Mus pups well in groups of less than about six. One additional measure taken to increase acceptance of the Mus pups by their foster mothers was a tumbling procedure. In the experimenter's freshly washed hands, the Mus pups being fostered and the foster-species pups were tumbled together for about $3 \mathrm{~min}$. In-species-fostered Mus were also similarly tumbled together.

At 25 days of age, 2 male Mus from each of 18 litters were weaned, weighed, and individually housed in a reversed-light-cycle room (lights on at $2230 \mathrm{~h}$, off at $1230 \mathrm{~h}$, dim red light on continuously). The room contained no adult rodents. At this time, each subject was assigned a five-digit random number for identification purposes.

Apparatus. The mice were tested in $25-\mathrm{cm}$-diameter $\times 15-\mathrm{cm}$ deep metal cans (see Figure 1). Four stimulus orifices (4-cm-diam

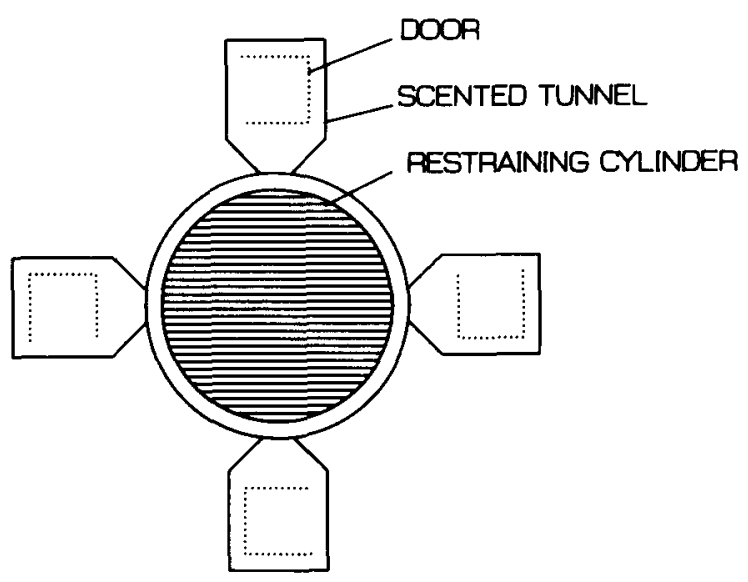

Figure 1. Top view of the scent-testing apparatus with the restraining cylinder in place. holes, 4-8 cm above the floor) were cut equidistant from one another around the circumference of each apparatus. Each orifice was fitted with a stimulus tunnel, constructed from a plastic water bottle, $9 \mathrm{~cm}$ deep and $6 \mathrm{~cm}$ square, with a $2.5-\mathrm{cm}$ opening. A 4-cm-square flap was cut into the top of each tunnel to ease insertion of the odor source and to facilitate cleaning.

Odor sources. Adult male house mice, deer mice, and rats were individually housed. In an attempt to equate the quantities of odorants deposited on bedding, the amount of bedding (Ab-sorb-dri wood chips) placed in each donor's cage was proportional to its species' mean daily food consumption. Data collected earlier indicated that Peromyscus ate an average of $2.5 \mathrm{~g}$ of chow per day, Mus ate $5 \mathrm{~g}$, and Rattus ate $20 \mathrm{~g}$. Accordingly, $150 \mathrm{ml}$ of bedding was placed in each Peromyscus cage, $300 \mathrm{ml}$ in each Mus cage, and $1,200 \mathrm{ml}$ in each Rattus cage. Bedding was not changed for 10 days prior to its use in testing.

Testing. Testing for response to conspecific scent took place when subjects reached 35 days of age. On the morning of its test day, each subject was transferred from its home cage to the testing apparatus for $3.5 \mathrm{~h}$ of habituation. During this time, the stimulus tunnels were empty and the subject was prevented from entering the tunnels by being enclosed in a bottomless 18 -cm-diameter $\times 15$ cm-deep hardware cloth cylinder within the testing apparatus. Wood chips from the subject's home cage were spread about the floor of the testing apparatus to a depth of $2-3 \mathrm{~cm}$.

Within $1 \mathrm{~h}$ of the start of a testing session, soiled bedding was collected from the donor animals. Each donor was quickly removed from its cage, and its bedding was thoroughly stirred before being removed for use in the stimulus tunnels. Within $5 \mathrm{~min}$ of the start of each test, approximately $50 \mathrm{ml}$ of odor source was placed in each stimulus tunnel through the opening in the top; the flap was then put back down and secured. Each tunnel received a different odor source: clean bedding, or bedding soiled by an isolated male Rattus, Peromyscus, or Mus.

Testing was done under dim red light during the first $4 \mathrm{~h}$ of the dark cycle. The 20 -min testing session started with the removal of the hardware cloth restraining cylinder: The cylinder was lifted, and a clear plastic top, with ventilation holes, was put in place. The mice were observed via a mirror positioned above the apparatus. An event recorder was used to record how much time each subject spent investigating each of the four tunnels (time spent with head and forelimbs, or at least half of the length of the body, within the tunnel) as well as latency to first visit and number of visits.

Twelve subjects from each rearing condition (Rattus-nursed, Peromyscus-nursed, and Mus-nursed) were tested, 2 for each of the six possible arrangements of scents about the circumference. To control for positioning of the apparatus within the room, at the beginning of each test, the apparatus was placed with the back of the clean tunnel pointing northward, and then was rotated a randomly selected $10 \times K^{\circ}$ clockwise, where $K$ is uniformly distributed from 0 to 35 .

At the termination of each testing session, the apparatus was cleaned thoroughly with a strong detergent (Airkem A-33) and then rinsed thoroughly and dried for its use the next day.

To minimize the contribution of experimenter bias, the only information available at the time of testing was the random identification number, the date the animal was to be tested, the tunnel arrangement to be used, and the number of degrees the apparatus was to be rotated.

\section{Results}

The basic design was a $3 \times 4$, nursing group $\times$ scent of tunnel analysis of variance (ANOVA). Nursing group was a three-level (Mus-, Peromyscus-, and Rattus-nursed) between-subjects factor, and scent of tunnel was a fourlevel (clean bedding, or Mus-, Peromyscus-, or Rattusscented bedding) within-subjects factor. The dependent 
variables were cumulative time spent in each tunnel, number of visits to each tunnel, and latency to first entry of each tunnel. A square-root transformation was used to normalize the within-cell distributions of the time and visits data, and a logarithmic transformation was used to normalize the latency data. Effects involving the scent factor were analyzed using the multivariate approach to within-subjects ANOVA. A .05 criterion for significance was employed. Pillai's trace was used in all multivariate tests of significance.

A doubly multivariate analysis simultaneously evaluating all three dependent variables revealed significant effects of nursing group $[F(6,64)=3.54, p=.004]$, scent of tunnel $[F(9,25)=4.73, p=.001]$, and the group $\times$ scent interaction $[F(18,52)=3.82, p<.001]$. When an effect is significant in a doubly multivariate analysis, it is then further analyzed with singly multivariate ANOVAs, one ANOVA per dependent variable. Effects that are not significant in a doubly multivariate analysis should be ignored in subsequent singly multivariate analyses. This strategy provides some protection against inflating alpha when evaluating multiple dependent variables. In each of the singly multivariate analyses, the significance of the interaction was evaluated first. When the interaction was significant, main effects were not evaluated but simple main effects were.

The singly multivariate ANOVA on the time variate (see the means in Table 1) revealed a significant interaction between nursing groups and scent of tunnel $[F(6,64)=$ $4.37, p<.001]$. Simple main-effects analysis indicated that the nursing groups did differ significantly on time spent in the Rattus-scented tunnel $[F(2,33)=12.86$, $p<.001]$, but not on time spent in the tunnels scented with clean bedding $[F(2,33)=0.13, p=.88]$, Mus odor $[F(2,33)=1.39, p=.26]$, or Peromyscus odor $[F(2,33)$ $=1.20, p=.31]$. A Student-Newman-Keuls test on the means involved in the one significant simple main effect indicated that the Rattus-nursed mice spent significantly more time in the Rattus-scented tunnel than did the Musnursed and the Peromyscus-nursed mice. The latter two groups did not differ significantly from one another.

Table 1

Mean Cumulative Time (in Seconds) Spent in Each of Four Tunnels

\begin{tabular}{lcccc}
\hline & \multicolumn{4}{c}{ Scent of Tunnel } \\
\cline { 2 - 5 } Nursing Group & Rattus & Peromyscus & Mus & Clean \\
\hline Rattus & 196 & 116 & 267 & 126 \\
Peromyscus & 36 & 207 & 495 & 169 \\
Mus & 44 & 266 & 276 & 150 \\
\hline
\end{tabular}

Table 2

Mean Number of Visits to Each of Four Tunnels

\begin{tabular}{lcccr}
\hline & \multicolumn{4}{c}{ Scent of Tunnel } \\
\cline { 2 - 5 } Nursing Group & Rattus & Peromyscus & \multicolumn{1}{c}{ Mus } & Clean \\
\hline Rattus & 12.75 & 7.92 & 10.50 & 10.25 \\
Peromyscus & 1.50 & 4.33 & 6.00 & 4.58 \\
Mus & 3.33 & 5.58 & 6.25 & 4.67 \\
\hline
\end{tabular}

The ANOVA on the visits variate (see the means in Table 2) also revealed a significant interaction $[F(6,64)=$ $3.71, p=.003]$. The nursing groups differed significantly on visits to the clean tunnel $[F(2,33)=4.54, p=.02]$ and to the Rattus-scented tunnel $[F(2,33)=22.98$, $p<.001]$, but not on visits to the tunnels scented with Mus $[F(2,33)=2.52, p=.10]$ or Peromyscus $[F(2,33)$ $=2.66, p=.09]$. Student-Newman-Keuls tests showed that the Rattus-nursed mice made significantly more visits to the clean tunnel and to the Rattus-scented tunnel than did the other two groups, which did not differ significantly from one another.

The pattern of significant results for the latency data exactly mirrors that for the time data, with the Rattusnursed mice entering the Rattus-scented tunnel significantly more quickly than did the mice in the other two groups.

\section{Discussion}

Exposing young rodents to artificial odors has been shown to alter their later response to conspecifics who have been scented with those odors (Fillion \& Blass, 1986; Marr \& Lilliston, 1969). These researchers have proposed that such results reflect the operation of an olfactory imprinting mechanism through which the young rodent learns to prefer (direct appetitive responses toward) the characteristic odors of its own species, much as young birds may learn the visual or auditory characteristics of their species. If such an olfactory imprinting hypothesis is correct, then isolating a young mouse from conspecifics should alter its later responsiveness to conspecfic odors.

In the current experiment, the Rattus-nursed and Peromyscus-nursed mice were isolated from adult conspecific scent, but the Mus-nursed mice were not. From the olfactory imprinting hypothesis, one would predict that, compared with the other groups, the Mus-nursed mice would spend more time in the Mus-scented tunnel, and, to the extent that time spent in the one tunnel cannot be spent in another tunnel, less time in the other tunnels. The fact that the groups did not differ significantly on response to the Mus-scented tunnel indicates that isolation from adult conspecific scent did not affect later response to conspecific scent.

Galef and Kaner (1980) reared rat pups artificially with greatly reduced exposure to conspecific scent. They found that such rearing did not affect later response to conspecific odors. They suggested that preferences for conspecific odors might be innate, might result from rapid imprinting near the time of birth, or might result from imprinting on one's own odors. Similar mechanisms could have prevented group differences in response to conspecific scent in the current experiment.

The present results clearly indicate that nursing experience affected the investigation of the Rattus-scented tunnels. Compared with the Mus-nursed and the Peromyscusnursed mice, the Rattus-nursed mice entered the Rattusscented tunnel more quickly, spent more time in the Rattus scented tunnel, and made more visits both to the clean and to the Rattus-scented tunnels. The increased response of the Rattus-nursed mice to the Rattus-scented tunnel can- 
not be attributed to their having been isolated from adult conspecific scents, since they differed significantly from the Peromyscus-nursed mice, who also were isolated from adult conspecific scent.

In addition to the spending more time in the Rattusscented tunnel, the Rattus-nursed mice were clearly more active than were the other mice, entering both the clean and the Rattus-scented tunnels more often than did the other mice. This heightened activity could be interpreted as a modified responsiveness to the scents present or a more general decrease in neophobia. However, Denenberg and his associates (Denenberg, Hudgens, \& Zarrow, 1964; Denenberg et al., 1968) reported that Rattus-nursed laboratory mice are less, not more, active in the open field.

\section{EXPERIMENT 2}

Experiment 1 showed that the response of house mice to the scent of rats can be altered by preweaning experience with rats. There are several mechanisms that could be involved in this change in response to rat scents. It may be that mere exposure to rat scents across the nursing period leads to the habituation of a fear response to rat scents. The association of rat scent with positive reinforcers (milk, warmth, contact comfort, tactile stimulation, etc.) may condition approach responses to rat scents. Alternatively, the effects of being reared by rats may not depend at all upon associative or nonassociative effects of exposure to rat scents. It may be that the parental care offered by a rat differs from that offered by house mice and deer mice in ways that produce lower neophobia, greater activity, or other changes that are more general and less stimulus-bound than just a change in response to the scent of rats. Experiment 2 was designed to determine whether exposing Mus-nursed pups to rat scents during their first 25 days of life would alter their responsiveness to rat scents.

\section{Method}

House mice and rats were bred, housed, and fostered as in Experiment 1, with 16 litters of house mice being fostered onto $M u s$ and 8 onto Rattus. Half of the Mus-fostered litters were maintained in cages atop the maternity rack in the Ratrus-colony room (Group MR); the other half were maintained in the Mus-colony room (Group MM). Each day, approximately $50 \mathrm{ml}$ of bedding was removed from each maternity cage and replaced with bedding (including freshly excreted feces) that had been collected from the nesting area of another mother and litter in the same stage of nursing (same number of days since birth of the pups) as the receiving mother and litter.

For the Rattus-nursed litters (Group RR) and Group MR, the transferred bedding was collected from Rattus mothers and pups, and for Group MM, it was collected from Mus mothers and pups. The transferred bedding was placed directly in the nesting area of each maternity cage. The transfer was done on Group MM and Group RR to control the degree of daily disruption among the groups.

The pups were weaned into a reversed-light-cycle isolation room, as was done in Experiment 1, and were tested in the same apparatus that was used in Experiment 1. Procedural details remained the same, with the following exceptions. The test was a two-scent test, with Rattus-scented bedding being placed in two tunnels $180^{\circ}$ from one another, and $M u s$-scented bedding placed in the remaining two tunnels. Tests were not for a fixed 20-min period as in Experiment 1, but continued for 15 min after each subject's first entry into a tunnel. Sixteen subjects from each group were tested.

\section{Results}

The bedding transfer did disturb the mothers, but they did not remove the alien feces, and so forth, from the nesting area, so the procedure was effective in producing longterm exposure to Rattus scents in Group MR.

Cumulative time data were normalized by a square root of $(X+.5)$ transformation and latency data by a $\log (X+1)$ transformation. Transformation of the number-of-visits data was not required. A multivariate group $\times$ scent analysis on the three dependent variables revealed significant effects of nursing group $[F(6,88)=3.71, p=.002]$, scent of tunnel $[F(3,43)=48.47, p<.001]$, and the group $\times$ scent interaction $[F(6,88)=8.19, p<.001]$. Univariate analyses indicated that the group $\times$ scent interaction was significant for the time variable $[F(2,45)=16.57$, $p<.001]$, the visits variable $[F(2,45)=17.39, p<$ $.001]$, and the latency variable $[F(2,45)=20.11, p<$ .0011 . Since the interactions were all significant, the main effects were disregarded and only the simple main effects were addressed.

The groups differed significantly on the amount of time spent in the Mus-scented tunnel $[F(2,45)=5.45, p=$ $.008]$ and in the Rattus-scented tunnel $[F(2,45)=25.63$, $p<.001$ ] (see Table 3). The effect on time spent in the Rattus-scented tunnel is clearly stronger than the effect on time spent in the Mus-scented tunnel. StudentNewman-Keuls tests showed that the Group RR mice spent significantly more time in the Rattus-scented tunnels than did Group MM and Group MR, the latter two groups not differing significantly from one another. The Group MR mice spent significantly more time in the Musscented tunnel than did Group RR. The mean for Group MM was an intermediate value that did not differ significantly from either of the other means.

The groups also differed significantly on number of visits to the Rattus-scented tunnel $[F(2,45)=35.50, p<$ $.001]$ but not on number of visits to the Mus-scented tunnel $[F(2,45)=0.05, p=.95]$ (see Table 3). StudentNewman-Keuls tests showed that the Group RR mice visited the Rattus-scented tunnels significantly more often than did Group MM or Group MR, the latter two groups not differing significantly from one another.

Table 3

Mean Time (in Seconds) Spent in and Number of Visits to Rattus-Scented and Mus-Scented Tunnels

\begin{tabular}{cccccc}
\hline & \multicolumn{2}{c}{ Time } & & \multicolumn{2}{c}{ Visits } \\
\cline { 2 - 3 } \cline { 5 - 5 } Group & Rattus & Mus & & Rattus & Mus \\
\hline RR & 274 & 327 & & 24.8 & 23.4 \\
MR & 53 & 553 & & 7.6 & 22.3 \\
MM & 64 & 477 & & 7.6 & 22.4 \\
\hline
\end{tabular}

Note-RR = Rattus-nursed litters; $M R=$ Mus-nursed litters maintained in Rattus-colony room; MM = Mus-fostered litters maintained in Muscolony room. 
The pattern of significant results for the latency data exactly mirrored that for the visits data, with Group RR entering the Rattus-scented tunnels significantly more quickly than did Group MM or Group MR.

\section{Discussion}

As in Experiment 1, being reared by rats resulted in the mice entering the Rattus-scented tunnels more quickly, spending more time there, and making more visits to that tunnel than did the other mice. Exposure of Mus-nursed mice to Rattus scents during their first 25 days of age did not produce any great change in their response to the scent of Rattus.

It is possible that the present methodology resulted in Group MR mice not merely being exposed to Rattus scents but also having such scents paired with fearproducing disturbance. The scent was most likely at its highest intensity immediately after each daily introduction of scented bedding, and such introductions did cause considerable disturbance, disrupting nursing and causing the mother and pups to flee from the nest. LeRoy, Roy, and Briley (1982) used a less intrusive means of introducing Rattus scent. They simply reared mice with their biological mothers in a rat-colony room. They found that such mice showed no preference on a rat- versus mousehuddling preference test at 36 days of age. Mice that had been reared in the mouse-colony room preferred to huddle with mice. Mice that had been nursed by rats in the rat-colony room preferred to huddle with rats.

\section{GENERAL DISCUSSION}

The two experiments reported here clearly demonstrate that being fostered onto a rat affects a wild mouse's response to foster-specific scents. Since being reared by a deer mouse did not affect response to foster-specific scent, it seems that early isolation from adult conspecifics was not the critical factor.

It is likely that an individual's behavior in the scented tunnel is affected by a host of subject variables that are in turn affected by cross-species fostering. For example, rat-reared mice may be, for reasons not directly related to their early exposure to rat scents, less neophobic and more active in a novel environment than are Mus-reared mice. These differences could stem from the different quality/quantity of maternal care received by rat-nursed mice. Others have reported that mere exposure to the scent of rats is not sufficient to produce the decreased corticosterone response to novelty found in mice reared by rats (Denenberg, Paschke, Zarrow, \& Rosenberg, 1969).

Early exposure of mouse-reared mice to the scents of rats did not affect their response to those scents, suggesting that species differences in maternal care might be more important than early exposure to contraspecific scent for producing the effects observed. An alternative explanation is that in the presence of adult scents from both con- specifics and contraspecifics, wild house mice imprint upon the conspecific scent and ignore the contraspecific scent. That is, isolation from adult conspecific scents may be necessary for exposure to contraspecific scents to have any great effect. Kuo (1960) reported that when a young animal is reared with both conspecifics and contraspecifics, it becomes more attached to the conspecifics than to the contraspecifics. Perhaps there is a tendency to imprint only on conspecific stimuli, if available, but on other stimuli in the absence of conspecific stimuli.

\section{REFERENCES}

Brown, R. E. (1985). The rodents: II. Suborder Myomorpha. In R. E Brown \& D. W. Macdonald (Eds.), Social odours in mammals (Vol. 1 , pp. 345-457). Oxford: Clarendon Press.

CARTER, R. L., \& BRAND, L. R. (1986). Species recognition in wildcaught, laboratory-reared and cross-fostered Peromyscus californicus and Peromyscus eremicus (Rodentia, Cricetidae). Animal Behavior, 34, 998-1066.

Denenberg, V. H., Hudgens, G. A., Zarrow, M. X. (1964). Mice reared with rats: Modification of behavior by early experience with another species. Science, 143, 380-381.

Denenberg, V. H., Paschke, R., Zarrow, M. X., \& Rosenberg, K. M. (1969). Mice reared with rats: Elimination of odors, vision, and audition as significant stimulus sources. Developmental Psychobiology, 2, 26-28.

Denenberg, V. H., Rosenberg, K. M., Paschke, R., Hess. J. L., Zarrow, M. X., \& Levine, S. (1968). Plasma corticosterone levels as a function of cross-species fostering and species differences. Endocrinology, 83, 900-902

D'Udine, B., Alleva, E. (1983). Early experience and sexual preferences in rodents. In P. Bateson (Ed.), Mate choice (pp. 311-327). Cambridge: Cambridge University Press.

FILlion, T. J., \& Blass, E. M. (1986). Infantile experience with suckling odors determines adult sexual behavior in male rats. Science, 231 , $729-731$.

GALEF, B. G., JR. (1982). Acquisition and waning of exposure-induced attraction to a nonnatural odor in rat pups. Developmental Psychobiology, 15, 479-490.

GAlef, B. G., JR., KANER, H. C. (1980). Establishment and maintenance of preference for natural and artificial olfactory stimuli in juvenile rats. Journal of Comparative \& Physiological Psychology, 94. 588-595.

Huck, U. W., BANks, E. M. (1980). The effects of cross-fostering on the behavior of two species of North American lemmings, Dicrostonyx groenlandicus and Lemmus trimucronatus: III. Agonistic behavior. Behaviour, 73, 261-276.

Kuo, Z. Y. (1960). Studies on the basic factors in animal fighting: VII. Inter-species coexistence in mammals. Journal of Genetic Psychology, 97, 211-225.

LeRoy, J. R., Roy, M. A., * Briley, S. M. (1982). Social preferences in mice influenced by ambient stimuli in the general rearing environment. Animal Behaviour, 30, 940-941.

Mainardi, D., Marsan, M., Pasqual, A. (1965). Causation of sexual preferences in the house mouse. The behaviour of mice reared by parents whose odour was artifically altered. Ant della Societd Italiana di Scienze Naturali, e del Museo Civile di Storia Naturale, 104, 325-338.

MARR, J. N., LILLISTON, L. G. (1969). Social attachment in rats by odor and age. Behaviour, 33, 277-282.

MCGuiRE, B. (1988). Effects of cross-fostering on parental behavior of meadow voles (Microtus pennsylvanicus). Journal of Mammalogy, 69, 332-341.

McGuire, B., NovAK, M. (1987). The effects of cross-fostering on 
the development of social preferences in meadow voles (Microtus pennsylvanicus). Behavioral \& Neural Biology, 47, 167-172.

StARK, B., \& HAZleTt, B. A. (1972). Effects of olfactory experience on aggression in Mus musculus and Peromyscus maniculatus. Behavioral Biology, 7, 265-269.

Wuensch, K. L. (1982). Effect of scented traps on captures of Mus musculus and Peromyscus maniculatus. Journal of Mammalogy, 63, 312-315.
WUENSCH, K. L. (1986). Development of responsiveness to conspecific scent in house mice: Effects of preweaning and postweaning experiences. Journal of General Psychology, 113, 65-73.

(Manuscript received July 4, 1991; revision accepted for publication February $7,1992$.

\title{
Editor's Change of Address
}

After a year at the University of Cambridge, Vincent M. LoLordo, Editor of Animal Learning \& Behavior, will be returning to Canada in August 1992. All manuscripts should therefore now be sent to him at:

\author{
Department of Psychology \\ Dalhousie University \\ Halifax, Nova Scotia B3H 4J1, Canada
}

